\title{
The method of smelting metals from charge with low metal content in a furnace with bottom electrodes and the first laboratory studies
}

\author{
Oleg Kazak ${ }^{1}$, and Ilya Starodumov ${ }^{1, *}$ \\ ${ }^{1}$ Laboratory of Multi-Scale Mathematical Modeling, Ural Federal University, Lenin ave., 51, \\ Ekaterinburg, 620000, Russia
}

\begin{abstract}
Liquid phase smelting reduction process for utilization of ferrous waste in the electric furnace with stationary bottom electrodes by carbon-thermal reduction is proposed and tested in laboratory conditions. The principal possibility of melting and reduction of iron heat generated in the slag bath between the bottom electrodes is shown.
\end{abstract}

\section{Introduction}

In the conditions of the high and unstable prices of scrap and crude iron, applied in steelsmelting production, there is an actual problem of using metallized charge, received not only from ore materials (DRI), but also from industrial ferrous waste (scale, slag, dust and sludge), as partial replacement of traditional types of charge materials. The technogenic waste saved up earlier and reproduced at the metallurgical enterprises makes actual development of new power effective ecologically safe technologies of their recycling.

Attempts of utilization of technogenic ferrous waste in the form of nonmetalized briquettes with addition of carbon contain reducing agent and binding by use those in the electric arc furnace charge instead of part of traditional scrap metal (up to 10-15\%) had no notable success [1]. Briquettes were destroyed because of the low mechanical strength and iron oxides almost completely passed into slag. Therefore metallization of oxide materials is represented necessary preliminary procedure of their recycling. DRI in world practice is produced by solid phase ("Midrex", "Energiron-HYL", "ITmk3" etc) and liquid phase processes ("Corex", "OxyCup" etc) [2] and the last are more productive and less critical to the quality of the initial charge. High capital intensity is a characteristic feature of all mentioned technologies provide economically accepted payback period at annual output no less 200 thousand tons of product. In the context of typical mini-mill is actual technology of recycling ferrous waste in more less amount corresponding to the volume of their formation (20-80 thousand tons per year) with a payback period of investment is not more than 1-2 years. None of mentioned processes does not meet these requirements, but "ITmk3 " and "OxyCup" seems the most acceptable forgiven purpose.

Process "ITmk-3" [3] is the production of iron in the form of melted pellets without using the coke and sinter. In the rotary hearth furnace pellets as a thin layer is charged

* Corresponding author: ilyastarodumov@yahoo.ca 
which made from metal waste, low-grade coal and binder. Pellets are heated to 1350-1450 ${ }^{0} \mathrm{C}$ in the furnace, iron recovers quickly, carburized and is partially melted. The whole process takes about $10 \mathrm{~min}$. The output produced granular iron with an iron content of 95$97 \%$. Energy consumption is $13.5 \mathrm{GJ} /$ ton of product. The disadvantages of the process applies its dependence on natural gas, which is used for heating furnace and high performance threshold, under the terms of an acceptable payback period - not less than 200 thousand tons per year.

Process of "OxyCup" [4] consists in reduction and melting briquettes in the shaft furnace, which contain technological ferrous waste, reducing agent in the form of coke breeze, lime as a flux and binder. The product is a liquid cast iron containing up to $4 \%$ carbon. The fuel and coke consumption are 1100-1200 Nm3 and 200-300 kg per 1 ton of product respectively. The process duration is about 1.5 hours. The disadvantages of technology are costly production of briquettes (mixer, press, drying), and also the lack of flexibility regarding the performance - not less than 200 thousand tons per year, which is associated with an acceptable payback period.

We conducted laboratory studies of two-stage process [5] of recycling waste iron in an electric arc furnace, in which the first stage of pre-reduction of compacted solid waste is carried out in the chamber, installed under the roof of electric arc furnace, by off-gases and second step is liquid phase reduction in a the molten bath to produce crude iron or steel semi-product. However, the problems associated with the volatility of the flue gas reduction potential and a combination of different physical nature of the stages in one unit, significantly impede achievement of high energy efficiency of technology.

\section{The methods description and first laboratory results}

The new technology of ferrous waste utilization [6, 7] base on liquid phase meltingreduction process in universal electrical furnace with stationary bottom electrodes, providing energy supply into molten slag bath. Process use carbothermic recovery of oxide materials, including technogenic waste in the furnace (fig. 1), where the main part of the energy, necessary for process, is allocated in the slag layer due to Joule heat. The technological scheme allows additional heat sources (exothermic reactions in bath due to oxygen blowing) and off-gas sensible heat partial utilization for preheating and prereducing of initial materials in the feeding shaft. In the case of using a direct current a certain development is gained by electrolysis.

The tests 1-3 were performed on an alternating current for the following electrical parameters: voltage $68-75 \mathrm{~V}$, current $1.75-1.90 \mathrm{kA}$, the test $4-$ on $\mathrm{DC}$ under the same electrical parameters to assess the role of electrolysis in the recovery process. As an initial charge tested following technogenic ferrous waste: in tests 1 and 4 rolling millsscale, in test 2 - blast furnace sludge, in test 3 - electric arc furnaces melting dust. As the reducing agent in tests 1-3 used low grade coal in an amount of $25 \%$ waste, as slag-forming - lime in an amount of $10 \%$ waste. In the test 4 carbonaceous reductant and purge by oxygen was not used. The final product of the process was liquid crude iron.

According to data, the overall specific energy consumption was on a laboratory unit 12$13 \mathrm{MJ} / \mathrm{kg}$ of product, which corresponds to parameter of the "ITmk-3" process.

The experiments have shown the increased refractory wear near the bottom electrodes. The similar problems exist in DC EAF with bottom electrode [8]. The reason for the increased wear is connected with vortex flows of liquid metal caused by spatial non homogeneity of electro-magnetic fields and temperature. Therefore, the most important objective is to estimate the factors influencing on refractory wear near the bottom electrodes, in particular, electro-vortex factors. 


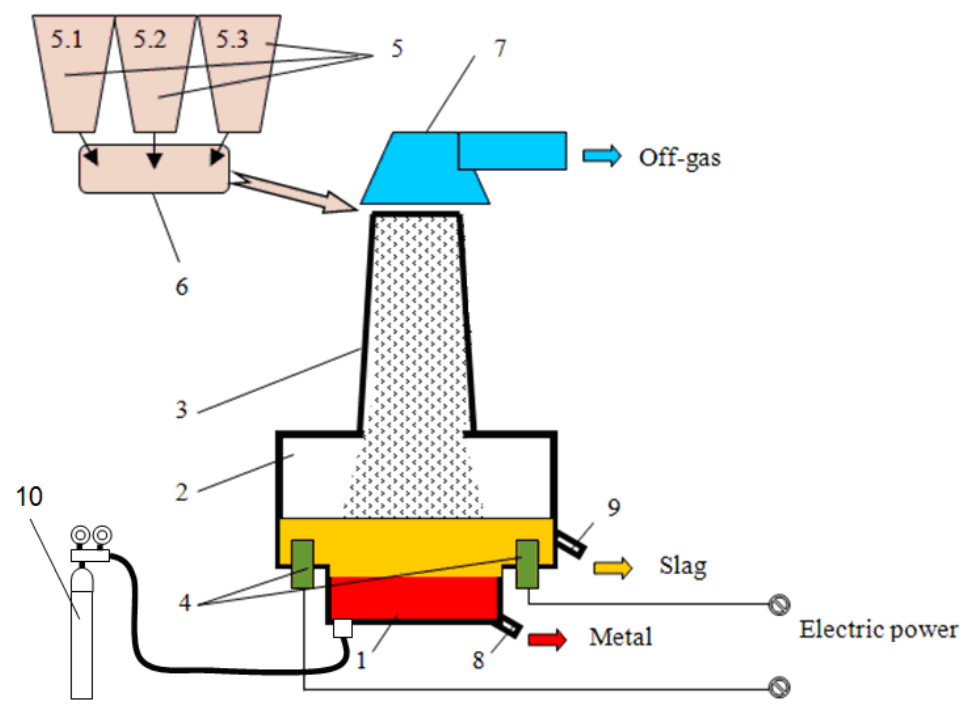

Fig. 1. Scheme of the electric furnace and the process. 1 - forehearth, 2 - furnace body, 3 - charging shaft, 4 - bottom electrodes, 5 - hoppers for ferrous wastes (5.1), coke (5.2) and fluxes (5.3), 6 mixer, 7 - off-gas removal system, 8 - metal tap-hole, 9 - slag tap-hole.

Liquid phase smelting reduction process in an electric furnace with bottom electrodes was tested in a laboratory unit $50 \mathrm{~kg}$ of the liquid metal. Operating parameters and results are given in Table 1.

Table 1. The operating data and results of experimental heats.

\begin{tabular}{|l|c|c|c|c|c|c|}
\hline \multirow{2}{*}{ Test№ } & \multicolumn{6}{|c|}{ Composition of initial waste, \% } \\
\cline { 2 - 7 } & $\begin{array}{c}\mathrm{Fe}_{2} \mathrm{O}_{3} \\
+\mathrm{FeO}\end{array}$ & $\begin{array}{c}\mathrm{CaO} \\
+\mathrm{MgO}\end{array}$ & $\mathrm{SiO}_{2}$ & $\mathrm{MnO}$ & $\mathrm{Zn}$ & $\mathrm{C}$ \\
\hline 1 & 90.9 & 1.0 & 3.2 & 0.4 & - & 0.26 \\
\hline 2 & 63.5 & 4.4 & 14.0 & 0.06 & 0.1 & 5.8 \\
\hline 3 & 66.8 & 6.9 & 8.6 & 0.2 & 1.5 & 9.4 \\
\hline 4 & 90.9 & 1.0 & 3.2 & 0.4 & - & 0.26 \\
\hline
\end{tabular}

\begin{tabular}{|l|c|c|c|c|c|c|}
\hline \multicolumn{7}{|c|}{ Composition of product (crude iron), \% } \\
\hline & $\mathrm{Fe}$ & $\mathrm{C}$ & $\mathrm{Mn}$ & $\mathrm{S}$ & $\mathrm{P}$ & $\mathrm{Zn}$ \\
\hline 1 & 96.5 & 2.2 & 0.32 & 0.040 & 0.08 & - \\
\hline 2 & 94.8 & 3.4 & 0.12 & 0.065 & 0.12 & 0.08 \\
\hline 3 & 94.6 & 4.1 & 0.14 & 0.055 & 0.11 & 0.34 \\
\hline 4 & 97.3 & 2.2 & 0.33 & 0.040 & 0.08 & - \\
\hline
\end{tabular}

\begin{tabular}{|l|c|c|c|c|c|c|}
\hline \multicolumn{4}{|c|}{ Slag composition, \% } & \multicolumn{3}{c|}{ Mass, kg } \\
\hline & $\begin{array}{c}\mathrm{Fe}_{2} \mathrm{O}_{3} \\
+\mathrm{FeO}\end{array}$ & $\begin{array}{c}\mathrm{CaO} \\
+\mathrm{MgO}\end{array}$ & $\mathrm{SiO}_{2}$ & $\begin{array}{c}\text { Initial } \\
\text { waste }\end{array}$ & Product & Slag \\
\hline 1 & 9.4 & 64.5 & 11.9 & 42.0 & 27.5 & 6.5 \\
\hline 2 & $\mathbf{1 7 . 9}$ & 41.8 & 32.7 & 39.5 & 17.4 & 15.8 \\
\hline 3 & 15.2 & 40.3 & 33.8 & 38.9 & 15.7 & 13.4 \\
\hline 4 & 4.8 & 57.3 & 32.2 & 25.5 & 8.4 & 6.2 \\
\hline
\end{tabular}




\begin{tabular}{|l|c|c|c|c|}
\hline \multirow{2}{*}{} & \multirow{2}{*}{$\begin{array}{c}\text { Time of } \\
\text { melting, min. }\end{array}$} & \multirow{2}{*}{$\begin{array}{c}\text { Yield of } \\
\text { product, \% }\end{array}$} & \multicolumn{2}{|c|}{$\begin{array}{c}\text { Consumption on 1 kg of } \\
\text { product }\end{array}$} \\
\cline { 4 - 5 } & & & $\begin{array}{c}\text { Electricity, } \\
\mathrm{kW} / \mathrm{h}\end{array}$ & Oxygen, $\mathrm{m}^{3}$. \\
\hline 1 & 57 & 94 & 2.12 & 0.25 \\
\hline 2 & 68 & 76 & 2.25 & 0.28 \\
\hline 3 & 66 & 71 & 2.29 & 0.28 \\
\hline 4 & 125 & 48 & 4.54 & - \\
\hline
\end{tabular}

\section{Conclusions}

Liquid-phase carbon, thermal melting and recovery process in the electric furnace with bottom electrodes is developed and tested in the laboratory. Process isn't critical to a choice of charging ferrous materials: slag, dust and sludge domain and steelmaking.

Using the bottom electrode can significantly reduce investment costs for equipment, improve energy efficiency and environmental safety of the process.

The possibility of producing molten iron of the main types of man-made iron metallurgical wastes is shown. The yield is $71 \ldots 94 \%$, power consumption $2.12 \ldots 2.29$ $\mathrm{kWh} / \mathrm{t}$ of product, the total energy consumption $-12 \ldots 13 \mathrm{MJ} / \mathrm{kg}$ product. The possibility of recovery of copper from copper smelting slag waste production is shown.

The reported study was funded by RFBR, according to the research project No. 16-38-60172 mol_a_dk.

\section{References}

1. V.S. Antonov, F.M. Letuchih, P.Yu. Beljavsky, Proc. 8-th Steelmakers Congress in Moscow, pp. 270-273 (2005) (in Russian)

2. S. Seetharaman, A. McLean, R. Guthrie, Treatise on process metallurgy, volume 3: industrial processes, Part A (Elsevier Ltd, 2014)

3. H. Tanaka, R. Miyagawa, T. Harada, RHF Technologies, pp. 8-13 (2008)

4. Yu. Blatz, MPT Russian Edition, v. 2, pp. 6-13 (2005)

5. A.A. Trojansky, P.I. Tischenko, S.N. Timoshenko, A.P. Tischenko, Vestnik DonNTU: Metallurgy, v. 40, pp. 76-81 (2002) (in Russian)

6. P.I. Tischenko, S.N. Timoshenko, Proc. 21-th Int. Conf. "Innovative solutions to urgent problems of basic industries, the environment, energy and resource saving", v. 3, pp. 248-253 (2013) (in Russian)

7. P.I. Tischenko, M. Pavlicevic, A.A. Trojansky at al., Method of metals fusion and device for metals fusion, Patent Ukraine no. 201013890 (2011)

8. X. Liu, J. Zhou, H. Shi et al., Metallurgical and materials transactions B, v. 39, pp. 713-724 (2008) 